\title{
Effects of an Acute Dose of $L$-Arginine during Coronary Angiography in Patients with Chronic Renal Failure
}

\author{
A Randomized, Parallel, Double-Blind Clinical Trial
}

Hylton I. Millera Avi Dascalua Tovy A. Rassin ${ }^{a}$ Y. Wollman ${ }^{b}$

T. Chernichowsky ${ }^{b}$ A. lainab

aCatheterization Lab, Department of Cardiology, and b Department of Nephrology, Tel-Aviv Medical Center,

Tel Aviv, Israel

\section{Key Words}

Renal failure · Contrast media · L-Arginine · Angiography

\begin{abstract}
Background: Contrast media (CM) are nephrotoxic and might further worsen renal function in patients with chronic renal failure. L-Arginine, the substrate of nitric oxide, protects kidney function and may improve endothelial function in patients with coronary artery disease. Hypothesis: Acute administration of L-arginine in a subset of patients with combined coronary artery disease and impaired kidney function during coronary angiography might prevent superimposed acute renal failure. Methods: A double-blind study of patients with mild/ moderate chronic renal failure $(\mathrm{Cr}>1.7 \mathrm{mg} / \mathrm{dl})$ undergoing coronary angiography (meglumine ioxaglate) was conducted. Patients received either L-arginine $(300 \mathrm{mg} /$ $\mathrm{kg}$ ) or placebo and were followed for $48 \mathrm{~h}$. Cardiac hemodynamic parameters, renal function and nitric oxide production were sequentially recorded. Results - Primary and Secondary: Both groups experienced a decrease of creatinine clearance $48 \mathrm{~h}$ following the procedure $(p<$
\end{abstract}

0.05). Creatinine levels slightly increased following the administration of L-arginine $(p<0.05)$ but not in the placebo treated group. No changes of systemic and cardiac pressures, total peripheral resistance or cardiac output were recorded within and between the treatment and placebo groups. Conclusion: CM injection causes an impairment of renal function. Addition of intravenous Larginine during cardiac catheterizations in patients with chronic renal failure does not prevent $\mathrm{CM}$-induced nephrotoxicity and does not affect endothelial dysfunction in the particular population studied by the authors, i.e. patients with coronary artery disease (CAD) of various degrees, or suspicion of CAD and chronic mild renal failure.

Copyright $\odot 2003$ S. Karger AG, Basel

\section{Introduction}

Contrast media $(\mathrm{CM})$ are nephrotoxic, especially in patients with impaired renal damage, and often result in an acute superimposed renal failure [22]. CM detrimental effects are caused by direct cytotoxicity of both ionics and

\section{KARGER}

Fax + 41613061234 E-Mail karger@karger.ch www. karger.com
Prof. H.I. Miller, Director

Catheterization Lab, Department of Cardiology

Tel-Aviv Medical Center

Tel Aviv, 64329 (Israel)

Tel.+972 3 6973395, Fax +972 3 6962334, E-Mail himiller@tasmc.health.gov.il 
nonionics and by hyperosmolarity (ionics) [9, 24]. Intravascular administration of CM can produce acute hemodynamic changes characterized by an increase in renal vascular resistance and a decrease in the glomerular filtration rate [21]. CM might as well induce pathophysiologic changes in the kidney, such as hypoxic tubular injury [20]. Ultimately, these effects might cause contrast nephrotoxicity [27]. It is estimated that CM-induced nephrotoxicity is the third leading cause of renal failure in hospitalized patients [2].

In order to protect the high-risk population of patients with chronic renal failure from CM-induced nephrotoxicity various approaches were used, such as hydration and mannitol [29], calcium channel blockers, adenosine antagonists, theophylline [20], acetylcysteine [30] and based on preliminary studies in animals and a weighty theoretical background, treatment with $L$-arginine [28].

$L$-Arginine is the natural precursor of nitric oxide (NO), a molecule participating in regulation of kidney function. NO might improve endothelial function in patients with coronary artery disease [6]. Since chronic renal failure patients have a low NO production [3] and accumulate natural inhibitors of NO synthesis [5], it is assumed that the addition of NO precursors to chronic renal failure patients may be beneficial. In animal models administration of $L$-arginine increases glomerular filtration rate [19] and is renoprotective in a radiocontrastinduced renal failure model in rats [28]. In humans, a controversy exists, since $L$-arginine dietary intake prevents an age-related reduction of renal function [25] and on the other hand acute $L$-arginine administration does not improve arterial endothelial function in renal failure [8]. The role of $L$-arginine bolus addition in heart disease is not clearly defined either, since it was reported to improve myocardial perfusion in a subset of patients with angina pectoris [13] but it does not increase the exercise capacity in patients with chronic heart failure [18].

Accordingly we investigated the efficacy of intravenous $L$-arginine as a potentially protective agent during coronary angiography in a selected subset of patients with coronary artery disease and chronic renal failure.

\section{Patients and Methods}

\section{Study Design and Patient Entry Criteria}

A total of 42 patients with chronic renal failure (creatinine $>1.7 \mathrm{mg} / \mathrm{dl}$ ) (table 1), scheduled for cardiac catheterization were enrolled in the study. The study was designed to demonstrate whether $L$-arginine improves clinical safety of angiographic procedure in high-risk chronic renal failure patients and was conducted as a ran-
Table 1. Patients' characteristics (mean \pm SEM)

\begin{tabular}{lcc}
\hline & $\begin{array}{l}\text { Placebo } \\
(\mathrm{n}=21)\end{array}$ & $\begin{array}{l}\text { L-Arginine } \\
(\mathrm{n}=21)\end{array}$ \\
\hline Age & $72 \pm 7$ & $69 \pm 16$ \\
Males & 15 & 16 \\
Angina degree & 2.7 & 2.9 \\
Prior MI & 13 & 10 \\
Hypertension & 16 & 14 \\
Diabetes & 4 & 7 \\
Hyperlipidemia & 12 & 14 \\
Creatinine & $2.41 \pm 0.9$ & $2.58 \pm 0.7$ \\
Creatinine clearance & $35.7 \pm 4$ & $32.10 \pm 3$ \\
Mean CM injected volume, $\mathrm{ml}$ & 147 & 182
\end{tabular}

Values are given as $\mathrm{mg} / \mathrm{dl}$ for creatinine and $\mathrm{ml} / \mathrm{min}$ for creatinine clearance. No statistically significant differences in clinical characteristics exist between the placebo and treatment groups.

domized, single-center, double-blind trial, comparing pre-angiographic injection of $L$-arginine versus placebo, $0.9 \%$ saline. The study conformed to the principles outlined in the Declaration of Helsinki and the protocol was approved by the institutional Research and Ethics Committee.

\section{Protocol}

All patients signed an informed consent. Diagnostic coronary angiography was performed via the right femoral approach. All patients received a hydration protocol of $100 \mathrm{~cm}^{3} / \mathrm{h} 0.45 \%$ saline $12 \mathrm{~h}$ prior and post procedure. Routine coronary premedication included diazepam $2.5 \mathrm{mg}$ i.v. and nitroglycerin $300 \mu \mathrm{g}$ prior to the procedure. The study drug, $20 \mathrm{~g} \mathrm{~L}$-arginine diluted in $200 \mathrm{ml}$ saline, was infused into a peripheral vein over a period of 20-30 min prior to the angiographic examination. The coronary arteries were imaged with manual injections of $8-10 \mathrm{ml}$ contrast medium using preshaped catheters. A total of about $150-180 \mathrm{ml}$ of contrast medium (meglumine ioxaglate, Guerbet, France) was used. The left ventricle was visualized by the injection of $30 \mathrm{~cm}^{3}$ of contrast medium via a pigtail catheter and cardiac parameters were assessed. All cardiac parameters were measured after $L$-arginine administration and prior to CM injection. The patients were followed in-hospital for $72 \mathrm{~h}$. Daily laboratory determination of SMAC and creatinine clearance were performed. Plasma and urine nitrite and stable metabolites of nitric oxide (NO) were determined as previously described [3]. No statistically significant differences in baseline clinical characteristics were found between the placebo and treatment groups (table 1).

\section{Statistical Analysis}

The results are presented as mean \pm SEM. Comparisons were made using the ANOVA on ranks for inter- and intragroup assessment and paired t test as required (SigmaStat, Jandel, Java). 
Table 2. Influence of $L$-arginine administration on patients' hemodynamic functions

\begin{tabular}{lrr}
\hline & Placebo & Arginine \\
\hline Systolic BP 0 & $164 \pm 5.5$ & $171 \pm 4.7$ \\
Systolic BP 10 & $159 \pm 5.7$ & $164 \pm 4.3$ \\
Systolic BP 20 & $157 \pm 5.9$ & $162 \pm 5.1$ \\
Diastolic BP 0 & $70.2 \pm 2.0$ & $72 \pm 2.2$ \\
Diastolic BP 10 & $69.6 \pm 2.2$ & $70 \pm 2.5$ \\
Diastolic BP 20 & $69.3 \pm 2.2$ & $70 \pm 2.8$ \\
SP 0 & $166 \pm 5.7$ & $182 \pm 7.2$ \\
SP 10 & $161 \pm 6.1$ & $176 \pm 6.5$ \\
SP 20 & $160 \pm 5.8$ & $178 \pm 8.6$ \\
EDP 0 & $18.8 \pm 2.4$ & $21 \pm 1.8$ \\
EDP 10 & $17.8 \pm 2.2$ & $19.5 \pm 1.4$ \\
EDP 20 & $17.1 \pm 2.0$ & $20.4 \pm 1.6$ \\
CO 0 & $4.5 \pm 0.2$ & $4.4 \pm 0.2$ \\
CO 10 & $4.4 \pm 0.2$ & $4.5 \pm 0.2$ \\
CO 20 & $4.4 \pm 0.2$ & $4.6 \pm 0.3$ \\
TPR 0 & $1,915 \pm 77$ & $2,072 \pm 156$ \\
TPR 10 & $1,939 \pm 79$ & $1,959 \pm 130$ \\
TPR 20 & $1,993 \pm 98$ & $2,021 \pm 172$ \\
\hline
\end{tabular}

Comparisons were made within and between the treatment groups. Values are given as $\mathrm{mm} \mathrm{Hg}$ for blood pressure and [(dyn.s)/ $\mathrm{cm}^{5}$ ] for peripheral resistance. ' 0 ' time refers to measurements prior to $L$-arginine infusion. ' 10 ' and ' 20 ' refers to time in minutes after onset of $L$-arginine infusion.

\section{Results}

Patients' hemodynamic data following $L$-arginine administration is presented in table 2. No differences for placebo and $L$-arginine treatments were observed within each group or between groups for intraventricular pressure, systemic blood pressure, total peripheral resistance or cardiac output.Within $48 \mathrm{~h}$ from treatment the creatinine levels were elevated in the $L$-arginine treated group $(\mathrm{p}<0.05)$, but not in the placebo-saline administered patients (table 3 ). Urinary creatinine excretion did not differ between the treatment and placebo groups (data not shown). Creatinine clearance decreased in both treated and untreated groups within $48 \mathrm{~h}$ as compared to preangiography values $(p<0.05$, fig. 1a). The serum BUN did not differ between and within groups (fig. 1b).

The blood and urinary NO were without a significant change during the first $24 \mathrm{~h}$ after the procedure in the placebo-treated group. Following the $L$-arginine injection, blood NO, but not urinary NO, was significantly higher in the $L$-arginine-treated group immediately after the injection of arginine at the start of the cardiac procedure $(\mathrm{p}<$ 0.05 , table 3 ).

L-Arginine in Renal Failure Patients
Table 3. Influence of $L$-arginine administration on creatinine and nitric oxide concentrations (mean \pm SEM)

\begin{tabular}{lll}
\hline Serum creatinine, $\mathrm{mg} / \mathrm{ml}$ & Placebo & L-Arginine \\
\hline Baseline & $2.41 \pm 0.2$ & $2.58 \pm 0.2$ \\
$24 \mathrm{~h}$ & $2.40 \pm 0.3$ & $2.66 \pm 0.1$ \\
$48 \mathrm{~h}$ & $2.36 \pm 0.2$ & $2.81 \pm 0.2^{*}$ \\
\hline Blood NO '0' & $42.1 \pm 10.7$ & $54.9 \pm 7.0$ \\
Blood NO 24 h post-procedure & $42.6 \pm 8.8$ & $37.6 \pm 5.2^{*}$ \\
Urinary NO '0' & $674 \pm 199$ & $841 \pm 272$ \\
Urinary NO 24 h post-procedure & $518 \pm 119$ & $573 \pm 129$
\end{tabular}

Values are given as $\mathrm{mg} / \mathrm{dl}$ for creatinine and $\mu \mathrm{mol} / \mathrm{mg}$ creatinine for NO. Statistical comparisons were made within and between the treatment groups. $* \mathrm{p}>0.05$ only for serum creatinine as compared to $L$-arginine baseline.

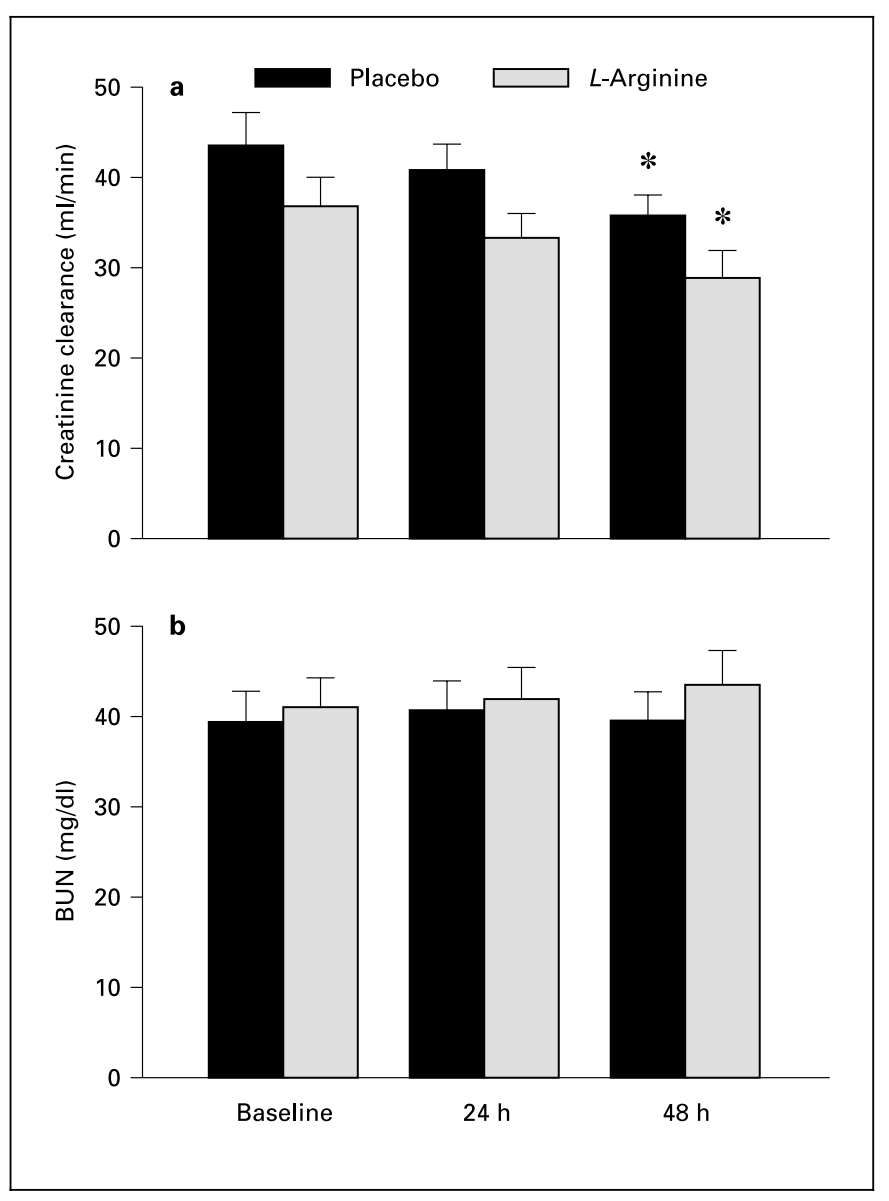

Fig. 1. Renal function of chronic renal failure patients after injection of contrast medium. a Creatinine clearance as compared to baselines of treated and untreated groups $(* \mathrm{p}>0.05)$. b BUN levels with or without $L$-arginine treatment.

Am J Nephrol 2003;23:91-95 


\section{Discussion}

The present study demonstrates that in a subset of patients with combined coronary artery disease and mildto-moderate chronic renal failure diagnostic angiography with ionic $\mathrm{CM}$ causes a decreased renal function. The administration of $L$-arginine during angiography prior to CM did not affect cardiac hemodynamics, nor did it prevent a $C M$-induced renal deterioration. The $L$-arginine-treated patients, unlike placebo-treated, had a slight increase of serum creatinine within $48 \mathrm{~h}$ from the catheterization procedure. However, none of the 42 subjects experienced acute renal failure necessitating dialysis treatment. This can be attributed to an appropriate preand post-angiography hydration protocol.

The rationale of the study is that contrast dyes reduce release of NO from endothelial cells of the renal vasculature [17]. Because exogenous sources of NO could in theory restore NO to the kidney, this maneuver may block a reduction in renal blood flow and thereby reduce the incidence of contrast nephropathy. At the molecular level, CM-induced damage might be related to changes of intracellular $\mathrm{pH}$ [9], mitochondrial dysfunction [15] or to direct apoptotic effects [33]. Vacuolization of cells is a preapoptotic sign in kidney and heart cells $[1,7]$ and it was reported in renal cells due to exposure to CM [31]. It is known that $\mathrm{CM}$ is involved in direct inhibition of $\mathrm{NO}$ production by endothelial cells [17] and reduces cortical NOS activity [16]. CM induces signs of subclinical nephrotoxicity in subjects with normal kidney function, altering markers of glomerular [11] tubular damage [12].

$L$-Arginine, the substrate of NO production, is supposedly deficient or its production is inhibited in coronary artery disease, contributing to endothelial dysfunction. This hypothesis leads to the assumption that provision of $L$-arginine could be a key element in endothelial function improvement [4]. L-Arginine infusion was reported to induce changes of diastolic blood pressure, cardiac output and peripheral vascular resistance in some studies, but not by others [14]. Our study sample did not show any significant acute hemodynamic changes due to $L$-arginine injection. We have employed about $0.3 \mathrm{~g} / \mathrm{kg}$ $L$-arginine dose and the lack of hemodynamic changes cannot be attributed to a sub-optimal $L$-arginine dosage. Other studies indicated that $L$-arginine was physiologically effective already at $0.1 \mathrm{~g} / \mathrm{kg}$ and elevated the renal plasma flow within $30 \mathrm{~min}$ of injection [26], due to its vasodilator effect and modulation of tubular sodium reabsorption.
The pathophysiologic changes induced by $\mathrm{CM}$ and their deleterious effects on the kidney have been amply described [21]. CM injection causes a hypoperfusion state due to renal vasoconstriction to be followed by further renal parenchymal hypoxia, resulting in a $12-27 \%$ risk renal nephrotoxicity in patients with impaired renal function. Unlike animal models, human studies demonstrate that administration of $L$-arginine in chronic renal failure patients does not improve renal function [10, 32]. We previously demonstrated a beneficial effect of $L$-arginine supplementation on preventing CM-induced acute renal failure in rats [28], and further inquired whether this finding can be duplicated in human subjects. The possible effect of $L$-arginine is to increase the systemic and intrarenal NO production (a possible increase of eNOS). Since a decreased NO production was documented in chronic renal failure patients, administration of $L$-arginine is supposed to have a beneficial effect in preventing the CMinduced superimposed acute renal failure. Our $L$-arginine treated subjects did not demonstrate a protective effect of $L$-arginine, as evidenced by a 48 -hour post-catheterization creatinine clearance decrease and even a slight increase of creatinine levels as compared to baseline values.

Few data reports examine endothelial dysfunction in the particular population studied by us, i.e. patients with coronary artery disease of various degrees and chronic renal failure. $L$-Arginine does not improve renal function in chronic renal failure patients, possibly due to the initial lack of significant endothelial dysfunction in these patients [8]. The lack of response in renal function does not seem to be due to the minimal acid load received by the $L$-arginine-treated group ( $200 \mathrm{ml}$ of saline vehicle at $\mathrm{pH}$ 5.5). A possible explanation to the inefficacy of $L$-arginine might be related to a high intraglomerular pressure (hyperfiltration state) existent in chronic renal failure resulting in no further NO production and no further haemodynamic effects due to addition of $L$-arginine. This may also explain an enhanced outer medullar NOS activity during $\mathrm{CM}$ administration as reported previously [16]. In addition, it was shown that administration of CM inhibits the NO production [17]. This might further explain the lack of improvement with $L$-arginine and the decrease in kidney function in the $L$-arginine treated group, a failure which might have been overcome by even higher doses of $L$-arginine injection. An alternative explanation to the elevation in creatinine in the arginine-treated group might be related to metabolites of arginine which can be converted to creatinine [23, 23]. 
Our study is limited by the lack of comparison of effects with different doses of $L$-arginine, the need to use other types of $\mathrm{CM}$, e.g. nonionics and the relatively small sample of patients. The administration of a bolus of $L$ arginine might not be sufficient to be effective and a prolonged infusion might be preferable. In summary, there is place for further clinical studies to investigate the lack of effect of $L$-arginine as a cytoprotector in patients with combined chronic renal failure and coronary artery disease undergoing coronary angiography. The in vitro/animal studies might not be relevant to clinical improvement in patients with both diseases who receive ionic CM.

\section{References}

1 Baroldi G: Different morphological types of myocardial cell death in man. Rec Adv Stud Cardiac Struct Metab 1975;6:383-397.

2 Berg KJ: Nephrotoxicity related to contrast media. Scand J Urol Nephrol 2000;34:317322.

3 Blum M, Yachnin T, Wollman Y, Chernihovsky T, Peer G, Grosskopf I, Kaplan E, Silverberg D, Cabili S, Iaina A: Low nitric oxide production in patients with chronic renal failure. Nephron 1998;79:265-268.

4 Boger RH, Bode-Boger SM: The clinical pharmacology of $L$-arginine. (review). Ann Rev Pharmacol Toxicol 2001;41:79-99.

5 Boger RH, Bode B: Asymmetric dimethylarginine, derangements of the endothelial nitric oxide synthase pathway, and cardiovascular diseases. Semin Thromb Hemost 2000;26: 539-545.

6 Boger RH, Bode B: The clinical pharmacology of $L$-arginine. Annu Rev Pharmacol Toxicol 2001;41:79-99.

7 Chiang ML, Hawkins EP, Berry PL, Barrish J, Hill LL: Diagnostic and prognostic significance of glomerular epithelial cell vacuolization and podocyte effacement in children with minimal lesion nephrotic syndrome and focal segmental glomerulosclerosis: An ultrastructural study. Clin Nephrol 1988;30:8-14.

8 Cross JM, Donald AE, Kharbanda R, Deanfield JE, Woolfson RG, MacAllister RJ: Acute administration of $L$-arginine does not improve arterial endothelial function in chronic renal failure. Kidney Int 2001;60:2318-2323.

9 Dascalu A, Peer A: Effects of radiologic contrast media on human endothelial and kidney cell lines: Intracellular $\mathrm{pH}$ and cytotoxicity. Acad Radiol 1994;1:145-150.

10 De N, Bellizzi V, Minutolo R, Andreucci M, Capuano A, Garibotto G, Corso G, Andreucci VE, Cianciaruso B: Randomized, doubleblind, placebo-controlled study of arginine supplementation in chronic renal failure. Kidney Int 1999;56:674-684.

11 Donadio C, Lucchesi A, Ardini M, Tramonti G, Chella P, Magagnini E, Bianchi C: Renal effects of cardiac angiography with different low-osmolar contrast media. Ren Fail 23:385396.

12 Duan SB, Wu HW, Luo JA, Liu FY: Assessment of renal function in the early stages of nephrotoxicity induced by iodinated contrast media. Nephron 1999;83:122-125.
13 Fujita H, Yamabe H, Yokoyama M: Effect of L-arginine administration on myocardial thallium-201 perfusion during exercise in patients with angina pectoris and normal coronary angiograms. J Nucl Cardiol 2000;7:97-102.

14 Goumas G, Tentolouris C, Tousoulis D, Stefanadis $\mathrm{C}$, Toutouzas $\mathrm{P}$ : Therapeutic modification of the $L$-arginine-eNOS pathway in cardiovascular diseases. Atherosclerosis 2001;154: 255-267.

15 Hardiek K, Katholi RE, Ramkumar V, Deitrick C: Proximal tubule cell response to radiographic contrast media. Am J Physiol Renal Physiol 2001;280:F61-F70.

16 Heyman SN, Goldfarb M, Carmeli F, Shina A, Rahmilewitz D, Brezis M: Effect of radiocontrast agents on intrarenal nitric oxide (NO) and NO synthase activity. Exp Nephrol 1998;6: 557-562.

17 Hutcheson IR, Griffith TM, Pitman MR, Towart R, Gregersen M, Refsum H, Karlsson JO: Iodinated radiographic contrast media inhibit shear stress- and agonist-evoked release of NO by the endothelium. Br J Pharmacol 1999;128: 451-457.

18 Kanaya Y, Nakamura M, Kobayashi N, Hiramori K: Effects of L-arginine on lower limb vasodilator reserve and exercise capacity in patients with chronic heart failure. Heart 1999; 81:512-517

19 Klahr S: Can $L$-arginine manipulation reduce renal disease? Semin Nephrol 1999;19:304309.

20 Morcos SK: Contrast media-induced nephrotoxicity - questions and answers. Br J Radiol 1998;71:357-365.

21 Morcos SK, Dawson P, Pearson JD, Jeremy JY, Davenport AP, Yates MS, Tirone P, Cipolla P, de H, Muschick P, Krause W, Refsum H, Emery CJ, Liss P, Nygren A, Haylor J, Pugh ND, Karlsson JO: The haemodynamic effects of iodinated water soluble radiographic contrast media: A review. Eur J Radiol 1998;29: 31-46.

22 Parfrey PS, Griffiths SM, Barrett BJ, Paul MD, Genge M, Withers J, Farid N, McManamon PJ: Contrast material-induced renal failure in patients with diabetes mellitus, renal insufficiency, or both: A prospective controlled study. N Engl J Med 1989;320:143-149.

23 Penttinen J, Pennanen S, Liesivuori J: Indicators of L-arginine metabolism and cardiovascular risk factors: A cross-sectional study in healthy middle-aged men. Amino Acids 2000; 18:199-206.
24 Potier M, Lagroye I, Lakhdar B, Cambar J, Idee JM: Comparative cytotoxicity of low- and high-osmolar contrast media to human fibroblasts and rat mesangial cells in culture. Invest Radiol 1997;32:621-626.

25 Reckelhoff JF, Kellum JA, Racusen LC, Hildebrandt DA: Long-term dietary supplementation with $L$-arginine prevents age-related reduction in renal function. Am J Physiol 1997; 272:R1768-R1774.

26 Schlaich MP, Jacobi J, John S, Delles C, Fleischmann I, Schmieder RE: Is 1-arginine infusion an adequate tool to assess endothelium-dependent vasodilation of the human renal vasculature? Clin Sci (Colch) 2000;99:293302 .

27 Schwab SJ, Hlatky MA, Pieper KS, Davidson CJ, Morris KG, Skelton TN, Bashore TM: Contrast nephrotoxicity: A randomized controlled trial of a nonionic and an ionic radiographic contrast agent. N Engl J Med 1989;320: 149-153.

28 Schwartz D, Blum M, Peer G, Wollman Y, Maree A, Serban I, Grosskopf I, Cabili S, Levo $\mathrm{Y}$, Iaina A: Role of nitric oxide (EDRF) in radiocontrast acute renal failure in rats. Am J Physiol 1994;267:F374-F379.

29 Solomon R, Werner C, Mann D, Elia J, Silva P: Effects of saline, mannitol, and furosemide to prevent acute decreases in renal function induced by radiocontrast agents. N Engl J Med 1994;331:1416-1420.

30 Tepel M, van d, Schwarzfeld C, Laufer U, Liermann D, Zidek W: Prevention of radiographiccontrast-agent-induced reductions in renal function by acetylcysteine. N Engl J Med 2000; 343:180-184

31 Tervahartiala P, Kivisaari L, Kivisaari R, Vehmas T, Virtanen I: Structural changes in the renal proximal tubular cells induced by iodinated contrast media. Nephron 1997;76:96102

32 Xiao S, Wagner L, Mahaney J, Baylis C: Uremic levels of urea inhibit $L$-arginine transport in cultured endothelial cells. Am J Physiol Renal Physiol 1901;280:F989-F995.

33 Zhang H, Holt CM, Malik N, Shepherd L, Morcos SK: Effects of radiographic contrast media on proliferation and apoptosis of human vascular endothelial cells. Br J Radiol 2000;73: 1034-1041. 